\title{
Abordaje percutáneo de la pielonefritis enfisematosa en riñón en herradura
}

\author{
DOI: https://doi.org/10.5377/alerta.v3i1.8481 \\ Neftalí Alexander Granados Flores ${ }^{1^{*}}$,José Alvarino Minero Ortiz ${ }^{2}$
}

\begin{abstract}
1. Doctor en medicina con especialidad en medicina interna, residente del departamento de radiología e imágenes del Hospital General y Hospital Médico Quirúrgico en el Instituto Salvadoreño del Seguro Social, San Salvador, El Salvador
\end{abstract}

2. Doctor en medicina, coordinador académico de la residencia de radiología e imágenes del Instituto Salvadoreño del Seguro Social.

${ }^{*}$ Correspondencia

$\square$ alexander_graflo@hotmail.com

(D) 0000-0002-6346-1977

\begin{abstract}
Resumen
La pielonefritis enfisematosa, más que una entidad poco frecuente, se considera subdiagnosticada, pues requiere gran agudeza clínica para su identificación. Se define como una complicación necrotizante del riñón, que pone en peligro la vida del paciente y que se caracteriza por la acumulación de gas en el parénquima renal y los tejidos vecinos. Este caso se presentó de forma epidemiológicamente atípica por tratarse de un hombre con una anomalía renal y del tracto urinario, el riñón en herradura, lo que vuelve aún más complejo el abordaje diagnóstico y manejo de esta patología.

Este caso es una referencia de la experiencia en el abordaje con catéter percutáneo como opción no tradicional de tratamiento. Se realizó una revisión de la literatura para tratar de comprender mejor las opciones en estudios de imagen para su diagnóstico y las características clínicas de esta afección, la cual sigue siendo controversial por tener una mortalidad $\tan$ alta.

Palabras clave

Riñón, enfisema, pielonefritis, catéter, percutáneo.
\end{abstract}

\begin{abstract}
Summary
Emphysematous pyelonephritis, rather than a rare entity, is considered underdiagnosed because it requires great clinical acuity for its identification; It is defined as a necrotizing complication of the kidney, which threats the life of the patient and is characterized by the accumulation of gas in the renal parenchyma and neighboring tissues. This case was presented epidemiologically atypical because it is a man with an abnormality of the kidney and urinary tract, such as the horseshoe kidney, which makes the diagnostic approach and management of this pathology even more complex.

This case is a reference of the experience in the approach with percutaneous catheter as a non-traditional treatment option; conducting a review of the literature to try to better understand the options in imaging studies for diagnosis and the clinical characteristics of this condition, which remains controversial for having such a high mortality.

Keywords

Kidney, emphysema, pyelonephritis, catheter, percutaneous.
\end{abstract}

\section{Introducción}

El término riñón en herradura se refiere a una anomalía no fatal del desarrollo renal por un defecto embriológico. La mayoría de los problemas clínicos en estos casos son originados por hidronefrosis y litiasis renal; ocurre en un $0.25 \%$ en la población general. Las indicaciones de cirugía en el riñón en herradura son la hidronefrosis secundaria a litos y obstrucción.
La primera descripción de infección de vías urinarias formadoras de gas fue en 1898 por Nelly y MacCallum. Posteriormente, en 1962, Schultz y Klorfein acuñan el término pielonefritis enfisematosa ${ }^{1,2}$ que se define como una grave afectación aguda y necrotizante del parénquima renal y tejidos perirrenales, causada por uropatógenos gram-negativos que se comportan como anaerobios facultativos en determinadas situaciones de baja concentración de oxígeno, creando f

ACCESO ABIERTO

Percutaneous approach

to emphyseatous

pyelonephritis in

horseshoe kidney. Case report

\section{Citación recomendada:}

Granados Flores NA, Minero

Ortíz JA. Abordaje percutáneo de la pielonefritis enfisematosa en riñón en herradura. Alerta 2020; 3(1):3-8

DOI: https://doi.org/10.5377/ alerta.v3i1.8481

\section{Contribución de autoría:}

NAGF': Diseño y elaboración del informe de caso. JAMO², revisión de caso clínico, drenaje percutáneo de paciente y elaboración de informe de caso.

\section{Recibido:}

9 de octubre de 2019

\section{Aceptado:}

16 de diciembre de 2019

\section{Publicado:}

27 de enero de 2020

\section{Conflicto de intereses:}

Los autores no tienen conflicto de intereses. 


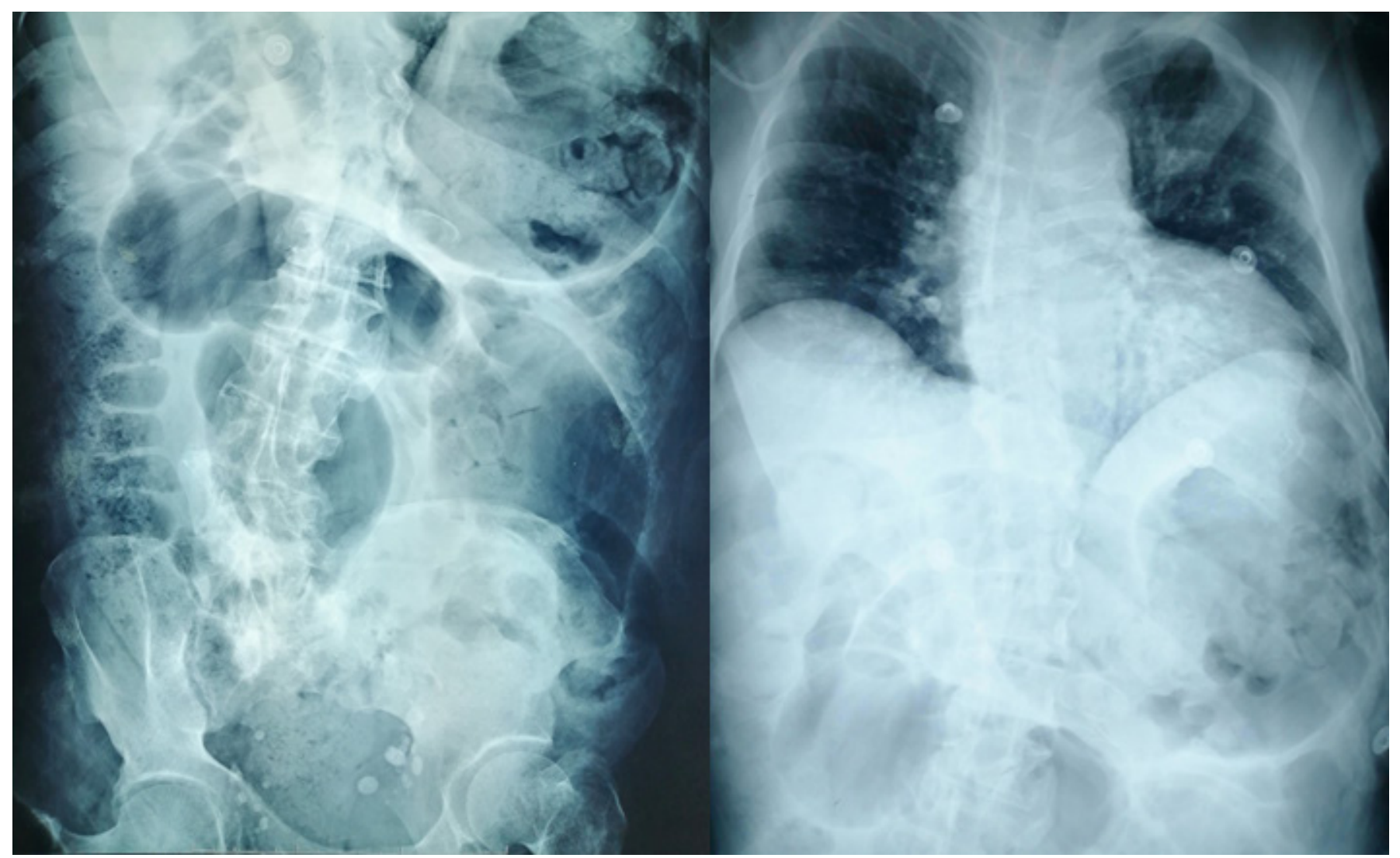

Figura 1. Serie abdominal presenta asas intestinales distendidas con nivel hidroaéreo sin gas distal

una infección y produciendo gas por mecanismos aún no esclarecidos ${ }^{3}$.

\section{Caso clínico}

\section{Información del paciente}

Paciente masculino de 68 años, diabético tipo 2 e hipertenso crónico de larga evolución, en controles en el Hospital de Especialidades del Instituto Salvadoreño del Seguro Social (ISSS); con antecedente desde la infancia de riñón en herradura, espina bífida y vejiga neurogénica.

Había presentado múltiples ingresos por infecciones de vías urinarias en unidad médica periférica, donde permaneció ingresado por cinco días por mismo cuadro. Referido al Hospital General del ISSS con diagnóstico de abdomen agudo obstructivo por un día de iniciar distensión abdominal generalizada, dificultad a la defecación y malestar general, evaluado en servicios de cirugía general.

\section{Hallazgos clínicos}

La exploración física revela: temperatura $37.5^{\circ} \mathrm{C}$, frecuencia cardiaca de 98 latidos/ minuto y presión arterial 119/60 mmHg. Se describe consciente y orientado en las tres esferas, quejumbroso. A la auscultación car- diopulmonar presentaba 18 respiraciones/ minuto, sin hallazgos patológicos en ambos campos pulmonares, saturando $97 \%$. Abdomen con marcada distensión, no doloroso a la palpación, con marcada diástasis de rectos abdominales y sin signos de rebote. Al tacto rectal se encontraron heces impactadas, las cuales se extrajeron manualmente, colocan sonda nasogástrica e inician régimen peritoneal. Los datos analíticos mostraban: hemograma: hemoglobina $10.6 \mathrm{gr} / \mathrm{dl}$; leucocitos 22000/(mm3; neutrófilos 89.7\%; plaquetas 163.000, coagulación: TP 15.4 segundos, INR 1.4, bioquímica: urea $155 \mathrm{mg} /$ $\mathrm{dl}$; creatinina $4.5 \mathrm{mg} / \mathrm{dl}$; potasio $4.7 \mathrm{mEq} / \mathrm{l}$; sodio $128 \mathrm{MEq} / \mathrm{l}$; glucosa $330 \mathrm{mg} / \mathrm{dl}$; albumina 2.6; PCR 32.7. En el examen general de orina presenta: 8-10 hematíes/campo, leucocitos incontables/campo, esterasa leucocitaria 500 y glucosuria.

\section{Evaluación diagnóstica}

Se tomó inicialmente serie abdominal de rayos $X$, en la que presentan asas intestinales distendidas con nivel hidroaéreo sin lograr observar gas distal (Figura 1). El ultrasonido no fue concluyente debido a la interposición de gas que limitaba ventana acústica.

La falla renal limitaba la utilización de material contrastado, se decide realizar pielo-TC estudio adquirido en equipo Soma- 
tom Defininition 10, con técnica helicoidal y multicorte, realizando un barrido desde las cúpulas diafragmáticas hasta la porción superior de las crestas iliacas sin material de contraste, obteniendo imágenes axiales y reconstrucción MPR reportando en cortes coronal y sagital marcada dilatación de asas intestinales con material hipodenso y gas en su interior (Figura 2). Estudio se concluye con enfermedad renal crónica avanzada, ateromatosis de la aorta abdominal, colelitiasis y líquido libre en ambas goteras parietocolicas.

Pasó a laparotomía exploradora el 04/02/19. Dicho procedimiento duró aproximadamente dos horas, realizando incisión suprapélvica infraumbilical y describiendo los siguientes hallazgos: "masa retroperitoneal izquierda", con obstrucción desde el ángulo esplénico hasta el recto, abundante sangrado en capas $\pm 200 \mathrm{cc}$, con aparecimientos de pequeños hematomas en múltiples áreas del intestino delgado y grueso. Describen, además, masa que compromete íleon hasta fosa pélvica; realizan resección de íleon distal y confeccionan ileostomía. Se lava la cavidad, se retiran hematomas y verifican permeabilidad de ileostomía, se suturan y da por finalizado procedimiento sin mayores complicaciones. No se toman muestras para estudio histopatológico.

Deciden realizar resonancia magnética abdominal para complementar estudio, la cual se realiza sin administrar material de contraste, lo que limita el valor diagnóstico de la misma pero reportan: en secuencia T1, T2 se observa riñón en herradura aumentado de tamaño con bolsa hidronefrótica que mide $17 \times 13 \times 11 \mathrm{~cm}$, que condiciona desplazamiento anterolateral de asas intestinales, conteniendo material hiperintenso en T2 e hipointenso en T1, con restricción en la difusión con alto coeficiente en ADC con cambios inflamatorios perirrenales (Figura 3) que corresponde a hidronefrosis severa con nivel hidroaéreo más hidrouréter, el cual se extiende hasta unión ureterovesical donde reduce severamente su calibre secundario a engrosamiento concéntrico de la mucosa vesical. Además, reportan rotoescoliosis de convexidad derecha en columna lumbar, lodo biliar, ostomía permeable, líquido libre y gas en cavidad, dato que debió correlacionarse con antecedente quirúrgico de paciente.

\section{Intervención terapéutica}

Se enfoca inicialmente como cuadro de crisis hiperglucémica con infección urinaria complicada, más inestabilidad hemodinámica, por lo que se inició en el posoperatorio inmediato infusión de aminas vasoactivas a dosis bajas; presenta aumento progresivo de niveles de creatinina y descenso marcado de la diuresis.

Durante estancia en servicios de cirugía general del Hospital General del ISSS fue evaluado por Nefrología, Infectología y Urología, que recomendaron la colocación de sonda de nefrostomía, debido a los datos obstructivos reportados en resonancia magnética.

El 24/02/19 se colocó sonda de nefrostomía en región dorsal derecha, logrando drenaje inicial de orina de aspecto turbio, cuantificando 2300 cc en 24 horas. Dos días después se realiza reevaluación con tomografía para verificar adecuada posición de sonda de nefrostomía; se instila material de contraste a través de catéter percutáneo, observando opacificación del sistema colector y verificando el paso a través del uréter hasta la vejiga, se observa colección abscedada del lado izquierdo que ha disminuido en comparación del estudio previo pero que aún persiste. Se programa colocación de un catéter percutáneo multipropósito 8.5 French en flanco izquierdo dirigido hacia la colección, logrando drenar $150 \mathrm{cc}$ de material purulento espeso. Se brindó seguimiento diario del gasto reportado a través de catéter percutáneo.

\section{Seguimiento y resultados}

Durante la primera semana de estancia hospitalaria se logra corrección de estado hiperglucémico y desequilibrios hidroelectrolíticos. Posteriormente presenta cuadro de sangrado digestivo superior; se realiza endoscopia que reporta esofagitis severa, gastritis erosiva y gastroparesia. Completó una semana con inhibidores de bomba a doble dosis; se logra destete de aminas vasoactivas. Urología posteriormente realiza dilatación de la estenosis en la unión ureterovesical.

Fue evaluado por medicina interna por sospecha de cardiopatía isquémica, la cual, al completar estudio, fue descartada.

El cultivo de secreción tomado al momento de la colocación del catéter aísla a los cinco días de incubación E. coli, con enzimas betalactamasas de espectro extendido (BLEE) positiva y Acinetobacter baumannii multisensible que fue considerado contaminante; se suspende terapia antibiótica empírica y completa esquema con carbapenémicos según sensibilidad reportada.

El gasto total durante el tiempo que mantuvo el catéter en la colección fue de 3800 cc; y del catéter de nefrostomia fue de aproximadamente 2000 cc/día. Durante 


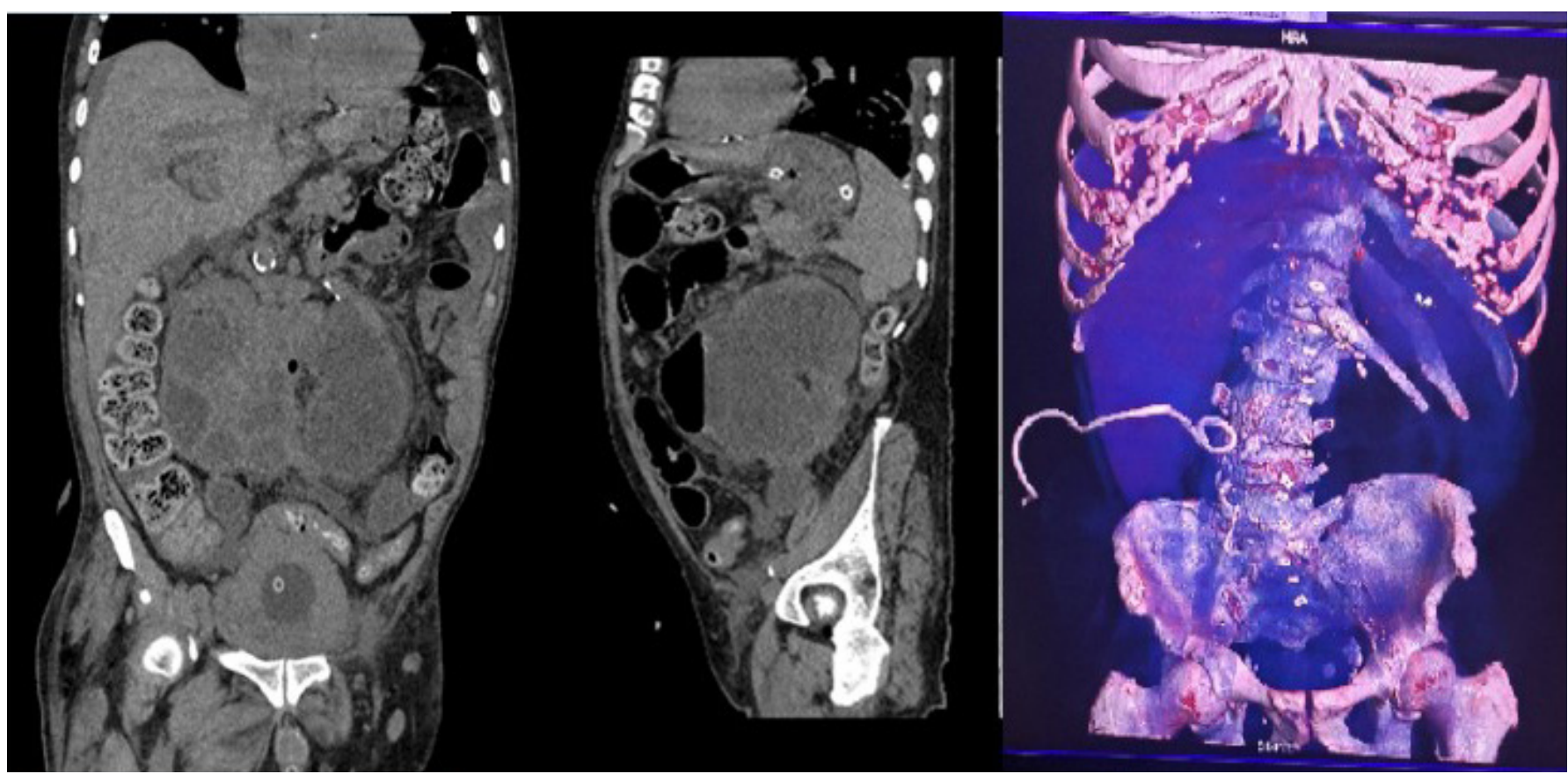

Figura 2. Se colocó catéter percutáneo guiado por ultrasonido como manejo mínimamente invasivo, para drenaje de material dentro de bolsa hidronefrótica y toma de muestras para cultivo.

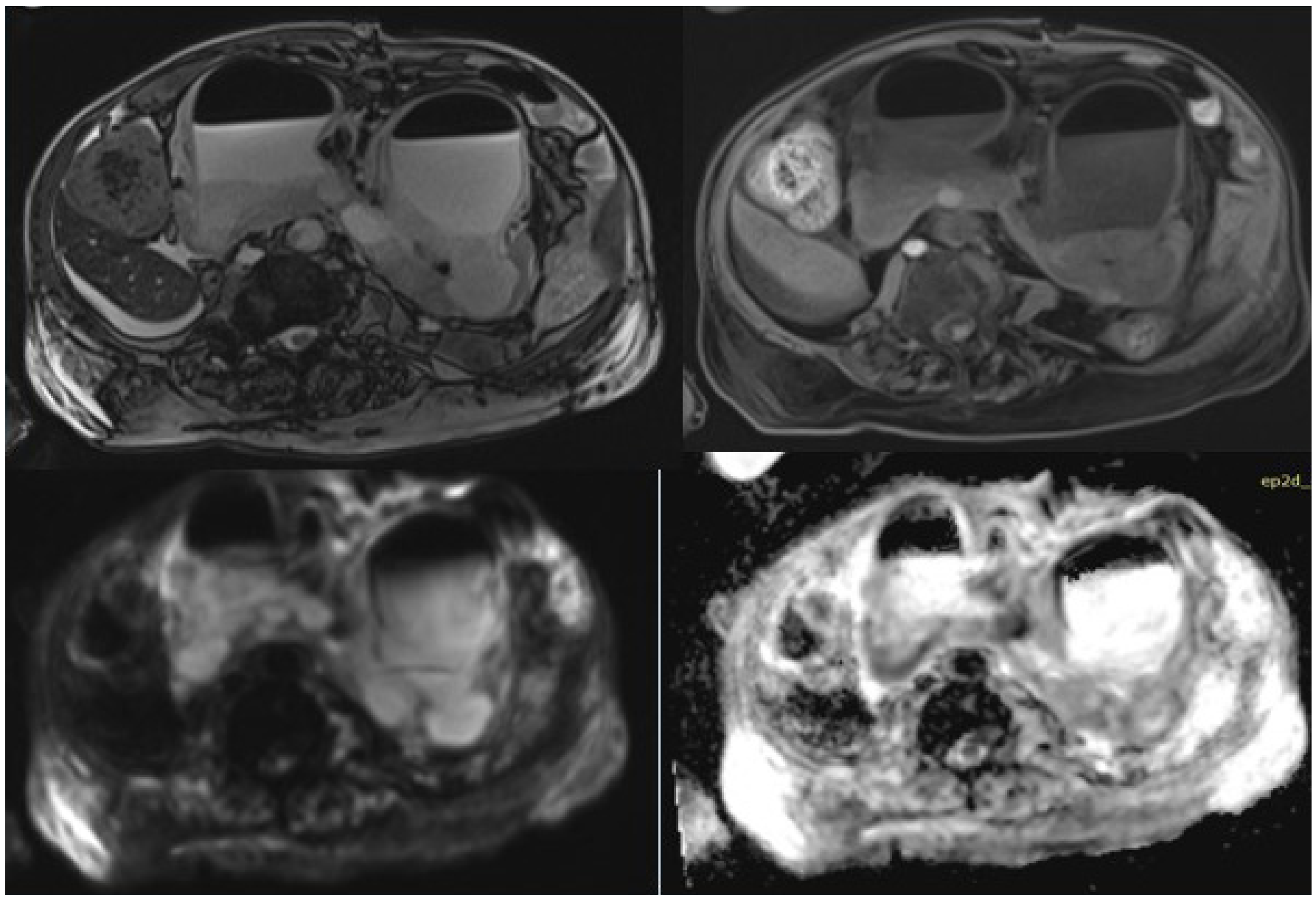

Figura 3. Resonancia magnética abdominal

(A-B) secuencia T1, T2 se observa riñón en herradura con bolsa hidronefrótica que contiene material hiperintenso en T2 e hipointenso en T1 que corresponde a liquido con nivel hidroaéreo. (C) Se identifica restricción en la difusión; (D) con alto coeficiente en ADC 
dicho tiempo se realizaron seguimientos tomográficos en fase simple para verificar adecuada posición de catéteres y evolución de la colección. No se reportaron acontecimientos adversos ni imprevistos; en exámenes control leucograma desciende a 8500/ $\mathrm{mm}^{3}$; creatinina sérica retorna a valores basales de $3.2 \mathrm{mg} / \mathrm{dl}$; persistió con hiponatremia leve $132 \mathrm{MEq} / \mathrm{l}$ y glucosa 180 mg/dl.

Al finalizar la cuarta semana intrahospitalaria, ileostomía permanecía permeable; el gasto de catéter en la colección desciende a cantidades mínimas. En rastreo tomográfico se verifica resolución de bolsa hidronefrótica; además, debido a la mejoría de la falla renal y el retorno de la diuresis espontánea, se decide retiro de ambos catéteres y alta hospitalaria.

\section{Discusión}

Respecto a la epidemiología de la pielonefritis enfisematosa, la media de edad se sitúa en torno a los 55 años. Es más frecuente en mujeres (aprox. $75 \%$ ) y aunque puede ocurir en pacientes no diabéticos, sobre todo se ha asociado a obstrucción ureteral (80\%), siendo aún más frecuente en diabetes mal controladas. Se presenta con cierto grado de disfunción renal o necrosis papilart-6.

Existen alrededor de 100 casos publicados en el mundo, lo cual refleja la escasa incidencia de este cuadro. Casi todos los pacientes presentan la típica triada de fiebre, vómitos y dolor, asociados en ocasiones a masa en el flanco?.

El diagnóstico raramente se establece por clínica y datos de laboratorio, por lo que es necesaria la realización de pruebas de imagen que revelan la existencia de gas intraparenquimatoso o perinefrítico ${ }^{8}$. Los métodos diagnósticos pueden ser la urografía intravenosa, la ecografía y la tomografía computarizada?. En el caso presentado se realizó ecografía renal como abordaje inicial, la cual no fue concluyente por la interposición de gas que se documentó mediante serie abdominal. Debido a la falla renal agudizada que presentaba el paciente, y aunque la tomografía con contraste endovenoso es el estudio de elección, se optó por realizar tomografía abdominal sin contraste (PieloTC), que se complementó para mejor caracterización de los hallazgos con resonancia magnética abdominopélvica.

Si bien es cierto que la actitud agresiva es un pilar fundamental en el manejo de esta patología, pues la mortalidad estimada reportada para los casos manejados de forma conservadora es del $80 \%$ y en los que se realiza tratamiento quirúrgico desciende hasta un 30\%10,11, la justificación para el procedimiento mínimamente invasivo, en este caso, se basó en que el estado hemodinámico del paciente no permitía un abordaje quirúrgico inmediato con márgenes de éxitos suficientemente seguros para ser considerado factible. Además, por la anomalía estructural del riñón del paciente, la pielonefritis equivale a una pielonefritis bilateral, casi como paciente monorreno, que son las únicas dos razones por los que se justifica este tipo de manejo ${ }^{12}$.

En este caso, el tratamiento médico resultó más adecuado para disminuir la morbimortalidad, preservar la masa y la función renal del paciente. Asimismo, siendo que la tasa de éxito reportada en la literatura para el drenaje percutáneo más antibióticos intravenosos es del $67 \%{ }^{13}$, el tratamiento percutáneo debe ser tomado en consideración como una opción viable dependiendo de las características clínicas de cada paciente.

\section{Aspectos éticos}

El presente artículo cuenta con acta del comité de ética. El caso presentado únicamente refleja información obtenida de los registros clínicos; no se realizó ninguna intervención o modificación intencionada de las variables biológicas, fisiológicas, sicológicas o sociales del paciente por parte del autor. Se consideró la confidencialidad de la información, el buen nombre de la institución y de los especialistas implicados en el caso.

\section{Consentimiento informado}

Se solicitó al comité de ética local eximir el consentimiento informado para la utilización de la información del paciente.

\section{Agradecimientos}

A Dra. Ethel Guadalupe Rivas Zuleta radióloga intervencionista y a Dra. Carolina Mena Merlos, por su ayuda en la intervención del caso.

\section{Fuentes de financiamiento}

No se contó con fuentes de financiamiento.

\section{Referencias Bibliográficas}

1. Gutiérrez M, Rodríguez F, Guerra JC. Anomalías renales de posición, forma y fusión: análisis radiológico. Revista de la Federación Ecuatoriana de Radiología. 2013; 6(1): 24-30 Disponible en: https://bit. Iy/2vlcDPs

2. Blanco Díez A, Barbagelata López A, Fernández Rosado E, Casas Muíño R, 
Chantada Abal V, González Martín M. Emphysematous pyelonephritis: case report and literature review. Actas Urol Esp. 2003;

27( 9 ): 721-725. Disponible en: https://doi. org/10.4321/s0210-48062003000900010

3. Ramírez Quiñones J, Novoa Mosquera M. Absceso cerebral complicado con ruptura intraventricular: reporte de dos casos y revisión de la literatura. An Fac med. 2014; 75(2):159-63. https://doi.org/10.15381/ anales.v75i2.8388

4. Ahlering TS, Boyd SD, Hamilton CL et al. Emphysematous pyelonephritis: a 5 year experience with 13 patients. J Urol. 1985; 134:1086-1088.

5. Ribot T, Bonsoms N, Prera A et al. Pielonefritis enfisematosa: una enfermedad que precisa un alto índice de sospecha para su diagnóstico precoz. Rev Clin Esp. 1992; 191:399.

6. Schaeffer AJ. Infections of the urinary tract. In: Walsh PC, Retik AB, Vaughan ED, Wein AS, editors. Campbell's Urology, 8th ed. Philadelphia. Saunders Company; 2002. p. 556-558.

7. Huang JJ, Tseng CC. Emphysematous pyelonephritis: Clinico-radiological classification, management, prognosis, and pathogenesis. Arch Intern Med. 2000; 160:797-805. DOI: https://doi.org/10.1001/ archinte.160.6.797

8. Blanco Díez A, Barbagelata Lopez A, Fernández Rosado E, Casas Muiño R, Chantada Abal V, González Martín M. Pielonefritis enfisematosa: Presentación de un caso y revisión de la literatura. Actas Urol Esp. 2003; 27(9):721-725. DOl: https://doi. org/10.4321/s0210-48062003000900010

9. Eloubeidi MA, Fowler VG Jr. Images in clinical medicine. Emphysematous pyelonephritis. N Engl J Med. 1999; 341:737. DOI: https:// doi.org/10.1056/nejm199909023411005

10. Shokeir AA, El-Azab M, Mohsen T, El-Diasty T. Emphysematous pyelonefphritis: a 15-year experience with 20 cases. Urology. 1997; 49:343-346. DOI: https://doi.org/10.1016/ s0090-4295(96)00501-8

11. Bonsoms N, Mancebo J, Blanch L et al. Pielonefritis enfisematosa: aportación de un caso y revisión de la literatura. Rev Clin Esp. 1992; 190:72-74.

12. Koh KB, Lam HS, Lee SH. Emphysematous pyelonephritis: drainage or nephrectomy? Br J Urol. 1993; 71:609-611.

13. Mas Gelabert M, Martin Martin S, González de Cabo M, Pardo Barro S, Ramos Alcaraz B, Martínez-Romillo MD, et al. Pielonefritis enfisematosa, diagnóstico por imagen de una entidad con graves consecuencias, con frecuencia oculta al clínico. Póster presentado en el 32 Congreso Nacional de la Sociedad Española de Radiología Médica 2014, 22-25 mayo. Oviedo, España. DOI: http://dx.doi.org/10.1594/ seram2014/S-0089 